\title{
Uma escola diferente do mundo lá fora
}

\author{
A different school of the world outside \\ Una escuela diferente del mundo exterior
}

MARGRID BURLIGA SAUER

KARLA SARAIVA

Resumo: $\mathrm{O}$ objetivo deste artigo é investigar porque os pais escolhem escolas militares para matricularem os filhos. A pesquisa foi desenvolvida em duas etapas. Os dados da primeira etapa permitiram compreender que a motivação dos pais para procurar a escola foi o bom desempenho em vestibulares e no ENEM, bem como seu sistema disciplinar. As entrevistas da segunda etapa mostram que os alunos gradativamente abandonam amigos e atividades que não estejam relacionadas à escola e que a rígida disciplina modifica não apenas os alunos, mas suas próprias famílias. O desempenho no vestibular apareceu também nesta segunda etapa e justifica os sacrifícios impostos pela disciplina.

Palavras-chave: disciplina; escolas militares; Ensino Médio.

Abstract: The purpose of this article is to investigate why parents choose military schools to enroll their children. The research developed in two stages. The data from the first stage allowed to understand that the major motivation of the parents was the well-recognized performance of the students in selections for admission to universities, as well as the current disciplinary system. The second stage of interviews shows that students gradually abandon friends and activities that are not related to the school and the rigid discipline modifies not only the students but their families itself. The performance in selections for admission to universities also appeared this second stage and justifies the sacrifices imposed by the discipline.

Keywords: Discipline, Military schools, High school.

Resumen: El propósito de este artículo es investigar por qué los padres eligen escuelas militares para inscribir a sus hijos. La investigación se desarrolló en dos etapas. Los datos de la primera etapa permitieron comprender que la motivación de los padres para buscar la escuela fue el desempeño en las selecciones para ingresar en las universidades, así como su sistema disciplinario. Las entrevistas de la segunda etapa muestran que los estudiantes abandonan gradualmente las amistades y las actividades que no están relacionadas con la escuela y que disciplina rígida modifica no solo a los estudiantes, sino a sus propias familias. El desempeño en la selectividad también apareció en esta segunda etapa y justifica los sacrificios impuestos por la disciplina.

Palabras-chave: disciplina; escuelas militares; escuela secundaria 


\section{INTRODUÇÃO}

O soldado é antes de tudo alguém que se reconhece de longe; que leva os sinais naturais de seu vigor e coragem, as marcas também de seu orgulho: seu corpo é o brasão de sua valentia

(FOUCAULT, 2007, p.117)

Nos últimos anos, diversos Estados brasileiros vêm entregando a gestão de escolas públicas à Polícia Militar, em um processo que está sendo denominado de militarização das escolas (BERTONI, 2015). Na página da Associação Nacional de Pós-graduação e Pesquisa em Educação (ANPED) encontra-se um artigo, de agosto de 2015, intitulado "Militarização" das escolas públicas - solução? (ANPED, 2015), apontando que a adoção desta estratégia visaria a implantar uma maior disciplina nas escolas, o que supostamente resultaria em redução da violência e melhora do desempenho dos alunos. Ainda de acordo com esse artigo, Goiás foi um dos estados pioneiros na militarização de escolas.

Guimarães e Lamos (2018) corroboram a análise da ANPED, afirmando, ainda, que a militarização das escolas brasileiras se dá principalmente em instituições situadas em zonas de periferia. Segundo os autores, a partir da implantação desse sistema, as escolas militarizadas passaram a exibir bons resultados em avaliações externas, como o Enem, consagrando o modelo junto à população. Desse modo, passaram a ser apresentadas como modelo de escola pública com qualidade de ensino e capaz de enfrentar o caos que aí se encontra. $\mathrm{O}$ artigo sinaliza que a população aceita abrir mão de uma escola democrática e submeter-se a uma organização militar em troca de melhor desempenho dos alunos.

A militarização das escolas tem ganhado força. No ano de 2019, logo após assumir a presidência da República, Jair Bolsonaro emitiu um decreto para reorientar a organização do Ministério da Educação. O Decreto $\mathrm{N}^{\circ}$ 9.465, de 2 de janeiro de 2019, em seu artigo 11, parágrafo XVI, determina que a Secretaria de Educação Básica tem como uma de suas atribuições

Promover, fomentar, acompanhar e avaliar, por meio de parcerias, a adoção por adesão do modelo de escolas cívicomilitares nos sistemas de ensino municipais, estaduais e distrital tendo como base a gestão administrativa, educacional e didáticopedagógica adotada por colégios militares do Exército, Polícias e Bombeiros Militares (BRASIL, 2019). 
No Rio Grande do Sul, não está ocorrendo um processo de militarização de escolas públicas, como descrito acima. Porém, desde 1980, existe em Porto Alegre o Colégio Tiradentes, subordinado à Brigada Militar ${ }^{1}$ e fundado no intuito de preparar jovens para ingressar futuramente em seus quadros (COLÉGIO TIRADENTES, 2018a). Gradativamente, a rede Tiradentes de escolas de Ensino Médio foi ampliada e atualmente existem seis outras escolas no interior do Estado. Portanto, apesar de não estar ocorrendo a militarização das escolas gaúchas, existe uma gradativa expansão de escolas militares (TENTARDINI, 2015).

Este artigo resulta de uma pesquisa ensejada pelas discussões em curso sobre a militarização das escolas. O objetivo é compreender as razões que levam as famílias a buscar que seus filhos estudem em uma escola militar fortemente disciplinar e como as famílias de alunos percebem os efeitos dessa disciplina. A questão foi inicialmente colocada tendo em vista que existe um crescente consenso de que a disciplina estaria perdendo espaço na sociedade contemporânea frente às novas configurações sociais, em especial do trabalho (SARAIVA, 2014).

A investigação foi desenvolvida com autorização da direção do Colégio e realizada em duas etapas: a primeira, por meio de entrevistas estruturadas com 41 responsáveis por candidatos que participaram do processo seletivo da escola e a segunda, por meio de entrevistas semiestruturadas com cinco mães de candidatos aprovados após um ano de ingresso. Na seção seguinte, apresentamos sucintamente o Colégio Tiradentes, de modo que os leitores tenham maior clareza sobre o perfil da instituição. A seguir, detalhamos a metodologia da pesquisa e, posteriormente, analisamos os dados produzidos. Por fim, tecemos algumas considerações acerca dos resultados obtidos nessa investigação.

\section{COLÉGIO TIRADENTES - CTBM}

A disciplina fabrica indivíduos; ela é a técnica específica de um poder que toma os indivíduos ao mesmo tempo como objetos e como instrumentos de seu exercício.

(FOUCAULT, 2007, p.143)

O Centro de Ensino Médio Tiradentes foi criado através do Decreto n ${ }^{\circ} 29.502 / 1980$, então com a denominação de Escola Estadual de $2^{\circ}$ Grau da Brigada Militar, passando a ter a denominação atual no ano de 2000. A Rede Estadual de Ensino Militar inclui sete estabelecimentos de ensino, localizados nas seguintes cidades: Porto Alegre, Passo Fundo, Santo Ângelo, São Gabriel, Pelotas, Santa Maria e Ijuí (COLÉGIO TIRADENTES, 2018a). O foco desta 
pesquisa é o Colégio Tiradentes de Porto Alegre, mantido pela Secretaria de Segurança Pública/RS e administrado por oficiais superiores, auxiliados por um efetivo militar especialmente designado pelo Comando da Brigada Militar. A coordenação pedagógica e alguns professores pertencem aos quadros da Brigada Militar e outros à Secretaria de Educação.

O Ensino Médio ministrado pelo Colégio Tiradentes destina-se à comunidade em geral,porém, com a reserva de trinta das noventa vagas existentes a dependentes de policiais militares, pois um de seus objetivos é a garantia de oferta educacional de qualidade a esse público. Nessa escola, o ingresso se dá por meio de um disputado concurso ${ }^{2}$. A primeira etapa da seleção para ingresso no Colégio Tiradentes é um exame intelectual, com questões de língua portuguesa e matemática. Os classificados nessa etapa passam por um exame de saúde e, posteriormente, por um teste físico, conforme critérios descritos no edital de seleção (COLÉGIO TIRADENTES, 2018d).

Os exames de saúde e testes físicos exigidos impedem o ingresso de alunos com deficiências, bem como aqueles com preparo físico considerado insuficiente (inclusive alunos considerados acima do peso ideal). No caso do Colégio Tiradentes, essas barreiras de entrada se encontram na Lei n ${ }^{\circ}$ 12.349/2005, que instituiu o Ensino Médio da Brigada Militar como "forma preparatória para o ingresso na carreira de policial militar" (ESTADO DO RIO GRANDE DO SUL, 2005), permitindo que sejam impostas restrições relativas às limitações físicas dos alunos.

Portanto, é possível afirmar que o Colégio Tiradentes não se configura como escola inclusiva, abrigando apenas alunos que mostram competências intelectuais e físicas avançadas. Frente a isso, o excelente desempenho que a escola tem em avaliações de larga escala, como o Enem, não pode ser creditado apenas às condições da escola em termos de infraestrutura bem acima da média e de uma rígida disciplina, pois seu corpo discente é composto por um conjunto de indivíduos muito homogêneo e com capacidade de alto desempenho.

A exclusão de alunos que não atendam aos padrões de exigência da instituição é parte daquilo que Foucault (2007) denominou de sistema disciplinar. Segundo este autor, a disciplina fixa os corpos no espaço e tende a segregar aqueles considerados anormais por não se enquadrarem nas exigências normativas. As escolas militares, bem como as militarizadas, são fortemente pautadas por uma organização disciplinar, ressoando as teorizações foucaultianas sobre o tema. Os alunos são controlados por um sistema que combina vigilância hierárquica, exames e sanções normalizadoras, os três instrumentos da disciplina, segundo o autor. Seus

2 Em geral, os concursos têm em torno de seis ou sete candidatos por vaga, sendo que para aqueles que não têm vínculos familiares com a Brigada Militar a dificuldade é maior. 
corpos seguem uma rígida distribuição espacial, o tempo é finamente fracionado e intensamente utilizado e os regulamentos prescrevem microfisicamente os comportamentos aceitáveis e as penalidades para as infrações. Nas análises que desenvolveremos posteriormente, esses elementos ficarão bastante evidentes. Contudo, antes de passarmos às análises, é necessário um maior detalhamento da metodologia de pesquisa adotada.

\section{OS CAMINHOS DA PESQUISA}

Pesquisas sobre a escolha da escola pelas famílias vêm sendo desenvolvidas desde os anos 1980 (RESENDE; NOGUEIRA; NOGUEIRA, 2011). Em geral, essas pesquisas buscam compreender como os diferentes extratos sociais, em diferentes países e culturas, orientam seu processo decisório sobre a educação dos filhos. Gostaríamos de destacar, entretanto, que nesta pesquisa não buscamos detectar a o perfil socioeconômico das famílias que procuram o Colégio Tiradentes, mas apenas o que os levou a essa escolha.

Conforme já mencionamos, esta pesquisa foi desenvolvida por meio de entrevistas, em uma primeira etapa, com os responsáveis por jovens que postulavam uma vaga nessa escola e, em uma segunda etapa, com responsáveis por jovens que já estudavam na instituição. A primeira etapa de produção de dados, desenvolvida em 22 de novembro de 2015, consistiu em entrevistas estruturadas com pais e mães enquanto aguardavam no pátio da escola por seus filhos e filhas, que realizavam naquele momento a prova de seleção para ingresso no $1^{\circ}$ ano do Ensino Médio. Na ocasião, cerca de 600 jovens participavam do processo seletivo para o preenchimento de 90 vagas.

A escolha pelo formato de entrevista estruturada se deu em função da necessidade de entrevistar o maior número de pais e mães possível, tendo em vista que a segunda etapa seria realizada apenas com aqueles cujos filhos tivessem sido aprovados e que concordassem em participar da continuidade da pesquisa. Ao se abordar um potencial sujeito da pesquisa, era exposto o objetivo do trabalho, sendo necessário seu consentimento para a realização da entrevista. Com isso, ao final da prova, haviam sido realizadas 41 entrevistas. Aqueles que manifestaram interesse em participar da segunda etapa da pesquisa forneceram espontaneamente seus nomes e telefones para que pudessem ser encontrados posteriormente.

Um ano após esta primeira etapa, voltamos a contatar os pais e mães entrevistados anteriormente e que haviam aceitado participar da segunda etapa. Aqueles cujos filhos haviam sido aprovados e estavam cursando o Ensino Médio no Colégio Tiradentes foram convidados a realizarem uma segunda entrevista, 
desta vez com formato semiestruturado, tendo em vista a necessidade de se explorar a relação dessas famílias com a disciplina imposta pelo Colégio. O primeiro contato para essa segunda etapa da pesquisa se deu por telefone, com o objetivo de agendar uma entrevista. Nesse contato, em 24 casos, os filhos não foram aprovados na seleção. Em dez casos, não foi possível obter retorno com o número informado. Nos sete casos de contato com responsáveis cujos filhos tinham sido aprovados, cinco mães se dispuseram a ser entrevistadas, um dos pais não quis participar e uma menina precisou sair do colégio porque engravidou, ficando fora do perfil selecionado para a pesquisa.

Novamente, foi solicitado o consentimento dos entrevistados, desta vez por meio de um Termo de Consentimento Livre e Esclarecido, apresentado após a exposição dos objetivos do trabalho e do modo como seria conduzida a entrevista. Houve somente um encontro com cada uma das cinco mães participantes. Das entrevistadas, três são mães de meninas e duas, de meninos. A seguir, analisamos os dados obtidos em cada uma das etapas da pesquisa.

\section{MAPEANDO OS CANDIDATOS AO COLÉGIO TIRADENTES}

Os dados produzidos na primeira etapa da pesquisa permitiram definir o perfil dos candidatos que buscam o Colégio Tiradentes. A maioria das questões desta primeira entrevista era objetiva. Houve um equilíbrio entre os gêneros daqueles que realizavam a prova, sendo $49 \%$ meninos e $51 \%$ meninas, e uma predominância de candidatos oriundos de escolas da rede pública de ensino, que perfaziam $63 \%$, sendo os demais oriundos da rede privada. Em $46 \%$ dos casos, a decisão de estudar no Colégio Tiradentes foi do próprio estudante, segundo afirmaram os familiares entrevistados, e 40\% vinham de famílias que tinham a presença de algum militar. Apenas $20 \%$ dos entrevistados declararam que os filhos poderiam ter algum problema de adaptação ao regime militar da escola, no caso de serem aprovados.

A entrevista estruturada era finalizada com uma questão aberta em que os pais deveriam apontar os motivos que levaram à escolha do Colégio Tiradentes. A análise das respostas permitiu mapear o que consta na Tabela 1. 


\section{Tabela 1 - Motivos para a escolha do Colégio Tiradentes - múltipla resposta}

\begin{tabular}{|l|c|c|}
\hline Motivos da escolha & Frequência & $\%$ \\
\hline Desempenho no vestibular & 25 & 61 \\
\hline Disciplina & 21 & 51 \\
\hline Pretende seguir a carreira Militar & 5 & 12 \\
\hline Segurança dentro da Escola/companhia & 4 & 10 \\
\hline Precariedade da Rede Pública & 4 & 10 \\
\hline Valores cívicos & 3 & 7 \\
\hline Bons colegas & 1 & 2 \\
\hline Infraestrutura do Colégio & 1 & 2 \\
\hline
\end{tabular}

Fonte: Dados colhidos pelas autoras

Na Tabela 1, os dados totalizam um valor maior do que $100 \%$, tendo em vista que na maioria das respostas foi possível identificar mais de um motivo para a escolha. Conforme os dados tabulados, o interesse pelo Colégio Tiradentes se deve, em primeiro lugar, ao forte desempenho da escola nos processos seletivos para o Ensino Superior. É importante sublinhar, como já o fizemos anteriormente, que esse bom desempenho não pode ser creditado somente às condições da escola, tendo em vista que o processo seletivo rigoroso cria uma barreira que permite a apenas alunos com potencial de alto desempenho frequentarem a escola. Se levarmos em conta que a valorização do desempenho nos processos seletivos está relacionada com a qualidade de ensino, é possível associar esse ponto às indicações sobre a precariedade da rede pública e com a boa infraestrutura do colégio.

Outro ponto amplamente destacado foi a disciplina da escola, que podemos conectar com outros que também estão na lista: segurança, boas companhias, valores cívicos e bons colegas. Nesse sentido, parece-nos que os pais veem a ordem fortemente disciplinar, que já não se manifesta de modo tão intenso em outras escolas, como uma salvação moral dos filhos. É importante notar que, apesar de a escola ter sido criada como preparação para ingresso na carreira militar, apenas $12 \%$ dos entrevistados manifestaram interesse nesse sentido.

Portanto, sintetizando os dados produzidos nesta etapa, é possível afirmar que as duas grandes motivações que levam a uma opção pelo Colégio Tiradentes é a qualidade de ensino, o que seria previsível para uma escola pública de alto desempenho em uma sociedade de alta competição por vagas no Ensino Superior, mas também a valorização da disciplina, questão que está no cerne das 
motivações desta pesquisa. Esses achados corroboram as discussões de Guimarães e Lamos (2018), que apontam para uma aprovação de métodos conservadores articulada com o desejo de bom desempenho escolar como o que constitui o apoio à militarização das escolas.

As entrevistas realizadas nessa primeira etapa permitiram conhecer um pouco melhor o público do Colégio Tiradentes e suas motivações, contribuindo para construir o instrumento que foi utilizado na etapa posterior.

\section{OS APROVADOS E SUA NOVA VIDA}

Esta segunda etapa, realizada aproximadamente um ano após a primeira, permitiu conhecer como cinco mães avaliavam a experiência dos filhos neste primeiro ano no Colégio Tiradentes. A partir dos dados produzidos nas entrevistas, construímos três focos de análise, que são apresentados a seguir: 'abandonando o mundo lá fora', 'disciplina para a vida' e 'desempenho no vestibular como passaporte para o futuro'. Cabe destacar que os focos de análise confirmam o que foi levantado na primeira etapa da pesquisa. Os dois primeiros focos estão relacionados à valorização da disciplina e o terceiro com a preocupação com os processos seletivos para o Ensino Superior.

\section{ABANDONANDO O MUNDO LÁ FORA}

As heterotopias sempre pressupõem um sistema de abrir e fechar que ao mesmo tempo as isola e as torna penetráveis. Em geral, não se entra nesses lugares à vontade. Ou a entrada é obrigatória, como no caso da caserna ou da prisão, ou então o indivíduo que tem que se submeter a rituais e purificações.

(FOUCAULT, 2003a, p.415)

A partir das entrevistas, foi possível perceber que, no decorrer deste primeiro ano, parece ter ocorrido uma separação desses jovens do mundo que está fora do Colégio. O que as mães relatam, por vezes com preocupação, ainda que disfarçadamente, é que seus filhos vão abandonando os amigos que não pertencem ao Colégio e deixam de se preocupar com celular, maquiagem, roupas ${ }^{3}$.

3 Optamos por transcrever os excertos das entrevistas sempre com recuo e em itálico por considerarmos que este recurso contribui para uma maior clareza. 
Mãe 1: Tem alguns pais [referindo-se às reuniões de pais e mestres], que ficam falando [entre eles] que os filhos não têm tempo para mais nada. Acham a escola puxada, "coitadinho". Mas eles não sabiam como era a metodologia da escola?

Pesquisadora: E seu filho, também tem pouco tempo para outras atividades, qual a sua opinião?

Mãe 1: Ele não tem mais tempo para ficar no Whats App, brincando no celular e coisas assim, como ficava antes. Agora está preocupado com os estudos. Eu acho que isso é bom!

O distanciamento do 'mundo lá fora' que o Colégio vai produzindo nos seus alunos marca a família e as relações que nela se estabelecem. O processo que o sistema altamente disciplinar, com cobranças rigorosas dos alunos, coloca em movimento faz pensar nesses sujeitos como 'incluídos' dentro do espaço do Colégio e 'excluídos', por assim dizer, do mundo que corre lá fora. Esta 'exclusão', mesmo que contingente, parece ocorrer com bastante força, moldando corpos e subjetividades.

Mãe 2: A exigência da escola acaba afastando eles da vida social. Isso no início foi um problema para ela, mas agora já está mais adaptada.

Pesquisadora: Ela não tem mais vida social?

Mãe 2: Tem, mas é menos que antes, quando saía mais com os colegas e ia ao cinema. Agora precisa estudar muito mais.

A convivência intensa do grupo entre si, que aparece como uma consequência do rigor disciplinar da escola, sinaliza que os alunos compartilham valores de conduta, morais e éticos de acordo com uma perspectiva interna ao grupo, promovendo a sua própria normalização. O Colégio retira os adolescentes da exterioridade, do convívio com aqueles que estão fora de seus muros, enquadrando-os em uma norma que lhe é própria e que se aloja nos corpos, acompanhando os alunos mesmo fora do ambiente escolar.

Mãe 3: O sistema educacional é excelente, é uma educação que não se vêe "ali fora".

Pesquisadora: O que, dessa educação, não se vê "ali fora"?

Mãe 3: A educação, o respeito, o coleguismo, responsabilidade. Eles aprendem a respeitar também o horário e a aceitar as regras. Se o horário é às $7 \mathrm{~h}$ é 7 h, não $7 \mathrm{~h}$ e 1 minuto, como temos o bábito de fazer.

A família também é envolvida pela disciplina da escola, poi,s para que as regras sejam respeitadas, os demais membros precisam compreender e aceitar o que é imposto pelo Colégio. E, pelo que pudemos perceber nas entrevistas, parece- 
nos que, em geral, os pais aceitam essas regras sem maiores questionamentos, reconhecendo, eventualmente, a superioridade dos comportamentos preconizados pela instituição em relação a seus próprios, como assinala a mãe no excerto acima. As normas disciplinares enquadram os alunos e, também, suas famílias.

Mãe 4: Essa questão de horário foi o que mais "pegou" a todos nós aqui em casa. Porque a gente pensa, são só cinco minutos! Não, até nas reuniões de pais, horário é cumprido à risca. Aos poucos, nós fomos nos adaptando a isso. Eu aprendi a cumprir horário, e aprendi isso com ele.

A aliança entre família e escola foi discutida por Comenius já no século XVII. Para esse educador, passada a primeira infância, os pais deveriam confiar a educação de seus filhos à escola, que seria planejada por especialistas capazes de dar-lhes uma melhor formação (NARODOWSKI, 2006). Nesse sentido, parecenos que o Colégio Tiradentes continua mobilizando essa aliança, ao impor às famílias seus valores e regras.

Mãe 2: A familia teve que se adaptar à rotina dela, que precisa estar de volta no colégio para o turno da tarde. As aulas lá iniciam às $7 \mathrm{~h}$ da manhã, então isso exigiu uma adaptação de horário. É preciso fazer o almoço dela, deixar tudo pronto para ela levar (marmita). Acabamos nos mudando para perto do colégio e isso facilitou um ponco essa questão dos horários dela.

A aliança da família com o Colégio fica evidenciada pela confiança necessária para submeter-se a uma disciplina tão rigorosa que chega a obrigar a uma mudança de endereço. É preciso uma forte crença de que este é o melhor caminho para a formação daqueles jovens. Muitos dos discursos acerca da escola contemporânea têm procurado mostrar o distanciamento dessa instituição dos modos de vida atuais. Há uma incessante busca por parte das escolas, e também dos indivíduos, de estratégias para lidar com a velocidade do mundo fora dos muros da instituição. E o que nos parece é que o Tiradentes está ainda mais desconectado com o que acontece fora de seus muros. Porém, dá-se ali um processo inverso, e o familiar que está 'fora' é que precisa se adaptar a quem está 'dentro' daqueles muros. O Colégio 'Tiradentes parece seguir com sua rigidez sem concessões a esse mundo líquido, mutável. Nesse sentido, o espaço do Colégio Tiradentes pode ser pensado como uma heterotopia foucaultiana, que, segundo o autor, são

Espécies de utopias efetivamente realizadas nas quais os posicionamentos reais, todos os outros posicionamentos reais que se podem encontrar no interior da cultura estão ao mesmo tempo representados, contestados, invertidos, espécies de lugares que estão fora de todos os lugares, embora eles sejam efetivamente localizáveis (FOUCAULT, 2003a, p.415). 
O Colégio Tiradentes, com seu desencaixe em relação à cultura atual, funcionaria como uma heterotopia que visa a resgatar valores e comportamentos que estão sendo deixados para trás nas sociedades contemporâneas. O ingresso nessa heterotopia, nesse lugar tão diferente dos outros lugares, exige uma transformação dos alunos, que é regrada pela própria escola. Eles passam por um período de adaptação de cerca de dois meses antes de serem definitivamente incorporados ao Colégio por meio de uma cerimônia em que devem mostrar que sabem conduzir-se adequadamente, fazendo continências e saudações e portando o uniforme de modo impecável. A pertença a esse lugar heterotópico exige esforços que visam a uma conversão de si que assegure sua integração aos valores e crenças da instituição. O caráter altamente ritualizado da incorporação à instituição é parte de um sistema disciplinar.

Portanto, no que foi possível observar ao longo das entrevistas, não só os alunos, mas a própria a família deve adaptar-se para que seja possível manter o filho ou a filha no Colégio Tiradentes. Deixar o 'mundo lá fora' e incorporar-se a essa heterotopia faz com que sejam necessários ajustes muitas vezes difíceis. Porém, a disciplina que é aprendida no Colégio Tiradentes, segundo as entrevistadas, será um bem que seus filhos levarão para a vida.

\section{DISCIPLINA PARA A VIDA}

Conforme Foucault (2007), no sistema disciplinar, o binômio "gratificação-sanção" se torna operante no processo de treinamento e correção, tendo a função de marcar os desvios e hierarquizar as qualidades, competências e aptidões (FOUCAULT, 2007). Este mecanismo se faz bastante presente no Colégio Tiradentes. Os alunos que se destacam por atingir os objetivos da instituição e por não incorrerem em falhas puníveis são condecorados com medalhas durante a formatura ${ }^{4}$ e podem até assumir o posto de comando da turma.

Para os que não atingem desempenho disciplinar ou escolar satisfatório, o regulamento do Colégio prevê uma série de sanções, chamadas de medidas disciplinares educativas, constantes do regulamento (COLÉGIO TIRADENTES, 2018c). As medidas disciplinares também são lidas durante a formatura. Portanto, no momento da formatura, os alunos que se destacam por se conduzirem segundo as normas da escola são premiados e aqueles que apresentaram desajustes têm suas punições publicizadas, constituindo-se aí um suplemento punitivo.

4 Formatura, na linguagem militar, significa a disposição ordenada dos corpos de uma tropa ou, no caso das escolas militares, dos alunos. 
De acordo com as mães entrevistadas, a disciplina presente neste Colégio vai preparar melhor seu filho ou filha para a vida e para o mercado de trabalho. Lembramos que, por ocasião da primeira etapa da pesquisa, $80 \%$ dos pesquisados disseram que os filhos ou filhas não teriam problemas de adaptação. Entretanto, na segunda etapa da pesquisa, as cinco participantes referiram que os filhos ou filhas, e também as famílias, encontraram dificuldades.

Mãe 2: A exigência da escola a pegou de surpresa, porque na outra escola ela tirava notas boas e quase não estudava. Então, achava que sabia tudo, que estava muito bem. Quando iniciaram as aulas, ela viu que não conseguia acompanhar o ritmo de exigências do colégio.

Porém, essas dificuldades são, em geral, significadas pelas entrevistadas como algo que produz bons resultados. Nesse sentido, as mães veem o zelo com o próprio uniforme, bem como o comprometimento com a manutenção e limpeza da escola, aprendizagens que transformam seus filhos positivamente e os preparam para a vida.

Mãe 3: Ela tem que limpar o sapato, tem que se responsabilizar pelo uniforme, e são diferentes uniformes. Foi caro comprar todos eles, tem o dia do uniforme completo, dia do abrigo, o cabelo precisa estar arrumado, puxado para usar a boina. Tudo isso são responsabilidades que ela acabou assumindo e isso prepara para a vida dela depois.

Mãe 4: Fiquei feliz de vê-lo tomando conta de suas coisas, cuidando daquele uniforme, nem me deixa passar. Ele dá valor, tem respeito [pelo uniforme]. Cumpre o que é combinado. Creio que isso a gente acaba relaxando na educação e lá ele aprendeu. Acho que todo o jovem devia passar por essa escola. Vejo que em outras escolas tem vandalismo, está tudo sujo, quebrado. Lá não tem isso e eles ajudam na limpeza da sala e do pátio do colégio.

Mãe 5: Ela aprendeu muito nesse último ano. Amadureceu, ficou mais responsável. Ela tem que cuidar do próprio uniforme, passar todos os dias, arrumar cabelo. Enfim, obrigações com as quais ela não estava acostumada. Eles limpam a sala, ajudam a limpar o pátio, recolhendo as folhas, são responsáveis em manter a sala de aula e aquele espaço em ordem.

Outra mãe declara que a disciplina é necessária para a vida, que regras são importantes e que estas devem ser cumpridas.

Mãe 1: A disciplina é necessária para a vida e as regras devem ser cumpridas. A escola é como o mercado de trabalho, tem regras e horários que precisam ser cumpridos. Acredito que isso vai tornar ele um profissional mais capacitado para enfrentar as adversidades do mundo. Tenho incentivado ele a estudar fora do país. Acho que essa escola só irá contribuir para isso. 
Percebemos, ao longo das entrevistas, uma defesa intensa do sistema disciplinar do Colégio. Parece-nos que essas mães querem livrar seus filhos da instabilidade de um mundo líquido (BAUMAN, 2014) com a solidez das normas disciplinares. Por meio da disciplina, esses jovens estariam tornando-se mais responsáveis, desenvolvendo habilidades importantes para a vida, inclusive para garantir o sucesso profissional. Para as entrevistadas, o duro sistema disciplinar potencializaria o "desempenho no vestibular", sendo o preço a pagar para garantir o ingresso em uma universidade pública.

\section{DESEMPENHO NO VESTIBULAR COMO PASSAPORTE PARA O FUTURO}

Desde o início desta pesquisa, ficou claro para nós que o ingresso numa universidade pública é o principal motivo da busca pelo Colégio Tiradentes. $\mathrm{Na}$ primeira etapa, 61\% dos familiares entrevistados responderam que a busca por uma vaga numa universidade pública, com ênfase na Universidade Federal do Rio Grande do Sul (UFRGS), era a razão de o filho ou filha estar participando da seleção. A maioria desses jovens (63\%) é oriunda da rede estadual de ensino, como mostramos na primeira etapa desta pesquisa. Tendo em vista o fraco desempenho das outras escolas dessa rede em processos seletivos, é compreensível a aspiração destas famílias. Na segunda etapa, das cinco mães entrevistadas, apenas uma referiu que o filho desejava estudar neste Colégio por pretender seguir a carreira militar.

Mãe 4: Ele era escoteiro, então ele que queria virpara esta escola, porque quer ser militar. Essa escolha é dele e quando vim conhecer o colégio eu me surpreendi com tudo o que vi. Ele fez a prova e rodou na primeira vez, e depois fez novamente. Nós apoiamos a decisão dele.

As demais mães apresentaram o ENEM e/ou vestibular, como motivo principal da procura pelo Colégio Tiradentes. Desse modo, os benefícios da disciplina e do abandono de atividades e relações fora da escola ficam subsumidos a esse grande objetivo de garantir o ingresso em uma universidade. Embora as falas tenham se concentrado mais na palavra vestibular como forma de acesso à universidade, elas percebem que um bom desempenho no ENEM também pode garantir acesso a instituições públicas de reconhecida qualidade, além de aumentar a probabilidade de acesso a instituições privadas pelo Programa Universidade Para Todos (ProUni). Em suma, as mães entendem que o Colégio Tiradentes é uma garantia de bom desempenho nesses processos seletivos de acesso ao ensino superior, seja ENEM, seja um concurso vestibular. 
Mãe 5: Queremos uma boa preparação para ela, para prestar o vestibular. Neste Colégio, eles ensinam com base nas provas de vestibular. Há toda uma preparação para isso. O processo [de seleção] é rigoroso e quem está lá, é porque quer estar lá.

Mãe 3: O Colégio Tiradentes tem ótimo desempenho no vestibular e no Enem. Sempre achei que esta fosse a melhor escola e depois dos resultados de vestibular desse ano eu não tenho mais nenbuma dúvida.

Mãe 1: O Colégio tem bom desempenho no vestibular, as provas do colégio já são no mesmo formato do vestibular, o que prepara o aluno para isso e en quero que ele vá se especializar fora do País, por isso buscamos a aprovação na UFRGS.

Tendo em vista o rigoroso processo seletivo por que passam os alunos do Colégio Tiradentes, acreditamos que eles possam ser tomados como aqueles que Bauman (2005) chama de válidos, ou seja, indivíduos com capacidade de encarnarem de forma modelar as virtudes do mundo atual, adaptando-se plenamente às regras sociais, em contraposição aos falhos, que não conseguem integrar-se adequadamente à ordem vigente. Esses alunos, mesmo oriundos, em sua maioria, de escolas estaduais que apresentam sérias deficiências, conseguiram superar essa limitação e obter uma vaga em uma acirrada disputa. Soma-se a essa vitória sua capacidade de adaptação às rígidas normas da escola, ficando evidenciado que elas podem ser consideradas válidas de acordo com a normatividade vigente. Porém, em alguns casos, os alunos, mesmo superando as dificuldades do processo seletivo, precisam passar por um processo de conversão que consolide sua validade, conforme demonstra o excerto abaixo.

Mãe 2: A busca foi pelo desempenho no vestibular. Ela provavelmente vai rodar nesse primeiro ano. Mas não faz mal, muitos iniciam no Tiradentes depois de já ter feito o primeiro ano em boas escolas de Porto Alegre. Ela já está lá dentro. Mesmo que rode, ano que vem será mais fácil. Ela é jovem, tem somente 15 anos. Então tem tempo para seguir em frente, e também ela vai ficar mais bem preparada para o vestibular da UFRGS, que é o objetivo.

Portanto, a aprovação no processo seletivo para ingresso no Colégio é apenas uma etapa inicial de um processo amplo de validação dos alunos. Ou seja, de conformação dos alunos a determinadas normas. A ideia de qualidade educacional no país, principalmente entre pais e alunos, está estreitamente ligada hoje ao desempenho em avaliações externas, em especial, ao desempenho em avaliações que constituem parte de processos seletivos para ingresso no ensino superior, tendo em vista a acirrada concorrência que se estabelece para a obtenção de vagas nas universidades e cursos mais disputados. Para muitas famílias, o indicador mais importante, senão o único, para a escolha da escola de Ensino Médio dos filhos é o desempenho em processos seletivos para o Ensino Superior. 
Nesse sentido, para essas famílias seria importante que a escola fosse capaz de proporcionar tanto um ensino de qualidade, quanto de disciplinar os alunos e mantê-los longe do mundo lá fora.

\section{CONSIDERAÇÕES FINAIS}

Desde o início da pesquisa, o que nos moveu foi a curiosidade sobre o papel desempenhado no mundo contemporâneo pelas escolas militares, fortemente disciplinares. Nossa atenção para o tema foi atraída pela crescente militarização de escolas públicas no país. Parecia-nos que se estava buscando soluções para problemas atuais no sistema disciplinar, que, segundo Foucault (2003b), caracterizou a Modernidade, mas estaria perdendo força no mundo contemporâneo.

Os resultados da primeira etapa da pesquisa já deixavam evidente a crença dos pais e das mães de que uma escola com mais disciplina poderia preparar melhor seus filhos e filhas para o vestibular, ou seja, que a preparação para enfrentar os processos seletivos não seria apenas fruto de um bom ensino dos conteúdos, mas também da orientação curricular fortemente disciplinar, que enfatiza a produção de sujeitos com um ethos orientado pelo senso de ordem e de dever.

Em relação à segunda etapa, foi possível perceber que a organização disciplinar transborda do ambiente escolar e se estende para o âmbito familiar. A disciplina cobra um preço que família e alunos pagam para maximizar a chance de ingresso numa universidade pública de qualidade, conforme foi possível observar durante a segunda fase da pesquisa. Não apenas pagam como o consideram justo por crerem que a disciplina é necessária para o sucesso não apenas nesse empreendimento, mas na vida de modo mais amplo. De acordo com as mães entrevistadas na segunda etapa da pesquisa, a disciplina que se faz presente no Colégio Tiradentes será um aprendizado para a vida. Além disso, a necessidade que as mães relataram de haver uma adaptação das famílias para que os filhos pudessem seguir as normas da escola sinalizam o desencaixe dessas normas com o funcionamento da sociedade atual.

Como em todos os sistemas disciplinares, no Colégio Tiradentes funciona um pequeno mecanismo penal (FOUCAULT, 2007), distribuindo sanções e prêmios que visam a normalizar os indivíduos. A disciplina se inscreve na superfície dos corpos. Nesse sentido, vale trazer a fala do comandante por ocasião da reunião inicial: "é bonito de ver aquele jovem que chega aqui civil e, dentro de alguns meses, percebe-se a mudança no corpo, na postura deles". A forte disciplina que rege os alunos do Tiradentes acaba por distanciá-los do mundo 
que está fora dos muros do Colégio, conforme relatam as mães entrevistadas. Os modos de vida dos jovens na contemporaneidade não parecem encontrar espaço na vida dos alunos desse Colégio, onde funcionam rígidas normas disciplinares.

Quando as mães entrevistadas se referem ao mundo lá fora, elas se referem a um mundo que se move. Lembrando o que escreve Bauman (2014, p. 77), "alguns dos habitantes do mundo estão em movimento; para os demais, é o mundo que se recusa a ficar parado". Parece haver nas falas das entrevistadas uma busca por uma ordem que foi perdida, uma crença de que a disciplina vai preparar melhor os filhos e filhas para o mundo e para o mercado de trabalho. Uma das mães justifica a escolha pelo Tiradentes "pela disciplina, pelo respeito e porque o mundo de hoje está perdido".

De acordo com Bujes (2012, p. 159), "a escola tem sido percebida como em descompasso com a sociedade que lhe corresponde. Ela não estaria mais dando conta de promover em seus alunos as condutas necessárias para que a sociedade atinja seus objetivos e concretize seus projetos". E esse desencaixe estaria, segundo a autora, fortemente ligado a uma herança disciplinar que ainda está presente nas instituições. Segundo Saraiva (2014), a escola contemporânea é chamada a transformar-se para continuar cumprindo uma função que já vem desde a Modernidade: produzir trabalhadores adaptados ao sistema produtivo e às formas de trabalho de seu tempo. A passagem de um sistema fabril calcado em um trabalho disciplinar para uma produção organizada por um trabalho flexível e imaterial exige outros tipos de subjetividade que a disciplina já não seria capaz de produzir.

Nesse sentido, a forte organização disciplinar do Colégio Tiradentes a tornaria ainda mais desencaixada do que as outras escolas? Ela não seria diferente apenas do mundo lá fora, mas também de outras escolas estaduais do RS, onde há greve, pichação, desordem, insegurança e uma baixíssima colocação no ranking do ENEM, na opinião das mães. Entretanto, se a expectativa da sociedade, como escreve Bujes (2012), é uma boa colocação no ranking final [vestibular], se esta é a 'caixa', estaria o Colégio Tiradentes encaixado? Ou será que, apesar de sua excelência nas avaliações, ele estaria desencaixado por promover modos de vida particulares que promovem uma socialização fechada sobre o grupo de alunos?

Aqui, é possível perceber um dos dilemas educacionais contemporâneos. A escola, inserida numa sociedade em que a disciplina tem cada vez menor destaque (FOUCAULT, 2003b), é conclamada continuamente a buscar formas de organização menos disciplinares, tanto em relação à disciplina-corpo, quanto em relação à disciplina-saber. Os projetos de aprendizagem, por exemplo, rompem com os princípios da fixação dos corpos, do corte da comunicação, da coletivização do uso do tempo, das fortes hierarquias características da disciplina- 
corpo e são fundamentados na ideia de interdisciplinaridade (SARAIVA, 2014). Essas novas formas de organização escolar estariam mais alinhadas com a forma com que os alunos aprendem e com as necessidades da sociedade atual, segundo o que vem sendo defendido por diversos autores.

Contudo, também é possível perceber que escolas fortemente disciplinares têm desempenhos destacados nas avaliações de larga escala. No cenário nacional, os colégios militares apresentam uma história de alto desempenho de alunos em concursos vestibulares e no ENEM, destacando-se entre as escolas públicas e fazendo frente a muitas escolas privadas. Um dos pontos de defesa da militarização das escolas em diversos Estados brasileiros é justamente a melhora de desempenho dos alunos, além da promoção de um ambiente mais ordeiro e seguro. Portanto, ao mesmo tempo em que se dissemina uma discursividade amplamente aceita acerca da necessidade de suavizar a disciplina na organização curricular para atender às novas geometrias do mundo, existe uma crescente pressão pelo desempenho em processos seletivos para o Ensino Superior que parece ser favorecido por um currículo fortemente disciplinar.

Desse modo, como já sinalizaram outras pesquisas, acreditamos que haja aprovação de instituições como o Colégio Tiradentes no contexto nacional, apesar de um desencaixe dos mecanismos disciplinares em relação aos modos de vida contemporâneos. A aprovação das mães entrevistadas à dura disciplina da escola, que isola os filhos do mundo lá fora, parece sinalizar que a solidez dos valores institucionais seja um alívio às angústias de como educar um filho em um mundo crescentemente líquido (BAUMAN, 2014).

Todavia, o mundo aqui fora requer sujeitos criativos, capazes de tomar decisões, de aprender autonomamente, de se mover num mundo fluido e cambiante. Para Saraiva e Veiga-Neto (2009, p. 192), na sociedade neoliberal "O cronômetro foi substituído por indicadores e a visibilidade se deslocou do corpo para o cumprimento de metas". Segundo esses autores, o trabalho imaterial modificou as atividades da cadeia produtiva e onde antes precisávamos de corpos dóceis, hoje temos a ênfase nos cérebros flexíveis e articulados. Além disso, o mundo contemporâneo é atravessado pela diversidade, exigindo capacidade de convívio com uma multidão de singularidades, o que parece ser o oposto do que ocorre no Colégio Tiradentes.

E talvez seja justamente este o desafio dos egressos desta escola: colocarse de volta no mundo aqui fora. Se a busca pelo vestibular é o que os move hoje, este é apenas um dos tantos desafios que irão enfrentar. Resta-nos questionar se a rigidez disciplinar é capaz de produzir um sujeito integrado nesse mundo cada vez menos disciplinar, mais líquido e em permanente transformação. E também o quanto de sofrimento eventualmente está sendo causado a esses alunos que 
deixaram o mundo lá fora e vivem em um outro mundo particular. Porém, estas são questões que fogem ao escopo desta investigação e que necessitam novos investimentos para serem respondidas.

\section{REFERÊNCIAS}

ANPED, Associação Nacional de Pós-graduação e Pesquisa em Educação. “Militarização" das escolas públicas - solução? Publicado em 03 ago. 2015. Disponível em: <http://www.anped.org.br/news/militarizacao-de-escolaspublicas-solucao $>$. Acesso em 03 jan. 2018.

BAUMAN, Zygmunt. Vidas desperdiçadas. Rio de Janeiro: Jorge Zahar Editor, 2005.

BAUMAN, Zygmunt. Modernidade Líquida. Rio de Janeiro: Jorge Zahar Editor, 2014.

BERTONI, Estevão. Cresce no Brasil o número de Escolas básicas públicas geridas pela PM. Folha de São Paulo, 10/08/2015. Disponível em: <http:// www1.folha.uol.com.br/educacao/2015/08/1666631-cresce-no-brasil-onumero-de-escolas-basicas-publicas-geridas-pela-pm.shtml>. Acesso em 08 jul. 2019.

BRASIL, Presidência da República. Decreto No 9.665, de 2 de janeiro de 2019. Disponível em <http://www.planalto.gov.br/ccivil_03/_ato2019-2022/2019/ Decreto/D9665.htm>. Acesso em 08 jul. 2019.

BUJES, Maria Isabel Edelweiss. Cultura da performatividade, expertise e os desencaixes da escola contemporânea. In: SARAIVA, Karla e MARCELLO, Fabiana A. (org). Estudos Culturais e Educação: Desafios atuais. Canoas: ULBRA, 2012, p 157-171.

COLÉGIO TIRADENTES. Institucional. Disponível em: <https://www. ctbmpa.com/institucional>. Acesso 03 jan. 2018a.

COLÉGIO TIRADENTES. Regulamento para o uso dos uniformes. Disponível em: <http://colegiotiradentes.g12.br/institucional/legislacao/ regulamento-de-uniformes>. Acesso 03 jan. 2018b. 
COlÉgiO TIRADEnTES. Cerimônia de Troca de Boinas. Postado em 26/04/2016. Disponível em: <http://colegiotiradentes.g12.br/formatura-deboinas-2016>. Acesso 03 jan. 2018.

COLÉGIOTIRADENTES. Regulamento disciplinar. Disponível em: $<$ http:/ / colegiotiradentes.g12.br/institucional/legislacao/regulamento-disciplinar/>. Acesso 03 jan. 2018c.

COLÉGIO TIRADENTES. Normatização do Processo Seletivo. Disponível em: $\quad<$ http://colegiotiradentes.g12.br/processo-seletivo-de-admissao-eclassificacao-para-ingresso-no-colegio-tiradentes-da-Brigada-Militar>. Acesso 03 jan. 2018d.

ESTADO DO RIO GRANDE DO SUL, Assembleia Legislativa. Lei No 12.349, de 26 de outubro de 2005. Disponível em <http://www.al.rs.gov.br/ filerepository/repLegis/arquivos/12.349.pdf>. Acesso em 08 jul. 2019.

FOUCAULT, Michel. Vigiar e Punir. Rio de Janeiro: Vozes, 2007.

FOUCAULT, Michel. Outros espaços. In: FOUCAULT, Michel. Ditos e escritos III - Estética: Literatura e pintura, música e cinema. Rio de Janeiro: Forense Universitária, 2003a. p. 411- 422.

FOUCAULT, Michel. A sociedade disciplinar em crise. In: FOUCAULT, Michel. Ditos e escritos IV - Estratégia poder-saber. Rio de Janeiro: Forense Universitária, 2003b. p. 267-269.

GUIMARÃES, Paula; LAMOS, Rodrigo. Militarização das escolas da rede estadual de Goiás: A nova onda conservadora. Revista Pedagógica, v.20, n.43, p. 66-80, jan./abr. 2018.

NARODOWSKI, Mariano. Comenius \& a Educação. Autêntica: Belo Horizonte: Autêntica, 2006.

RESENDE, Tânia; NOGUEIRA, Cláudio; NOGUEIRA, Maria Alice. Escolha do estabelecimento de ensino e perfis familiares: uma faceta a mais das desigualdades escolares. Educação \& Sociedade, v. 32, n. 117, p. 953-970, out./dez. 2011. 
SARAIVA, Karla; VEIGA-NETO, Alfredo. Modernidade Líquida, Capitalismo Cognitivo e Educação Contemporânea. Educação \& Realidade, vol. 34, n. 2, p. 187-201, maio/ago. 2009.

SARAIVA, Karla. A aliança biopolítica educação-trabalho. Pro-posições, v. 25, n. 2, p. 139-156, maio/ago. 2014.

TENTARDINI, Cleber Dione. Militarização da educação pública se expande no RS. Jornal Extra Classe. Sinpro/RS. 2015. Disponível em: http://www. extraclasse.org.br/edicoes/2010/04/Militarizacao-da-educacao-publica-seexpande-no-rs// Acesso em: nov./2015.

MARGRID BURLIGA SAUER é mestre em Educação (ULBRA) e graduada em Ciências Sociais (Unisinos). Atualmente é diretora de pesquisa do Amostra Instituto de Pesquisa.

E-mail: margridsauer@yahoo.com.br

ORCID: https://orcid.org/0000-0001-5548-8523

KARLA SARAIVA é Doutora em Educação (ULBRA), atualmente é professora do Curso de Pedagogia e do PPG em Educação da ULBRA.

E-mail: profa.karla.saraiva@gmail.com

ORCID: https://orcid.org/0000-0002-2105-0619

Recebido em agosto de 2019

Aprovado em setembro de 2019 